\title{
Notas sobre a tese da contemporaneidade dos jovens hegelianos
}

\author{
Luiz Repa*
}

Resumo: Trata-se de investigar o significado da tese habermasiana de que o discurso filosófico da modernidade permanece contemporâneo da primeira geração dos discípulos de Hegel, os quais estabeleceram, na seqüência da crítica do conceito hegeliano de razão, uma nova concepção de racionalidade histórica.

Palavras-chave: modernidade - razão - história - hegelianismo

Este texto pretende compreender a traços largos a tese habermasiana de que, após Hegel, a filosofia permaneceu contemporânea do pensamento dos jovens hegelianos. Com esta tese, posta no terceiro capítulo do Discurso filosófico da modernidade, Habermas procura reconstruir os traços característicos do discurso filosófico sobre a modernidade, após a ruptura provocada pelos jovens hegelianos com a filosofia hegeliana e com a tradição metafísica. Na verdade, os jovens hegelianos, como Feuerbach e Marx, radicalizam uma ruptura com a tradição filosófica que já está presente em Hegel, em particular em seu conceito de modernidade.

Poucas passagens da produção historiográfica sobre a filosofia contemporânea foram tão provocativas e sugestivas como o seguinte texto de Habermas: "Nós permanecemos até hoje na situação da consciência que os jovens hegelianos deram origem ao se distanciarem de Hegel e da filosofia em geral. Deste então, estão em circulação aqueles gestos triunfais de superação (Überbietung) recíproca, com os quais nós ignoramos o fato de que permanecemos contemporâneos dos jovens hegelianos. Hegel inaugurou o discurso da modernidade; mas só os jovens hegelianos o estabeleceram para perdurar. Ou seja, eles libertaram

* Mestrando do Departamento de Filosofia da Universidade de São Paulo e bolsista CAPES. 
do peso do conceito hegeliano de razão a figura de pensamento de uma crítica fecunda da modernidade nutrida pelo espírito da modernidade” (Habermas 1, p. 67; trad. p. 59). Quem está minimamente familiarizado com as peripécias da filosofia contemporânea reconhece logo nesta citação um lugar-comum da historiografia: a filosofia hegeliana como a última figura da galeria filosófica, designada costumeiramente pelo nome de metafísica, de philosophia perennis, ou de a grande filosofia. Hegel teria sido aquele que culminava a tradição e, ao mesmo tempo, trazia os motivos de uma ruptura. O que surpreende é a afirmação de que as muito diferentes filosofias pós-hegelianas tenham em comum esta posição de consciência facultada pelos jovens hegelianos, quando assumem formas do discurso sobre a modernidade. De que modo o fim da filosofia serviria de amálgama para correntes de pensamento tão distintas como a ontologia fundamental, a crítica, a genealogia, a dialética negativa e outras? A propósito dessa questão, pretendo apontar aqui o essencial na tese da contemporaneidade, recolocando as afirmações contidas na passagem citada no contexto da análise habermasiana. Parece-me então que a compreensão da tese de Habermas deve passar por questões óbvias: de que modo é possível entender que Hegel inaugurou o discurso da modernidade? O que motiva os jovens hegelianos a se afastarem da filosofia em geral? E, sobretudo, de que modo essas novas figuras do pensamento dão continuidade ao discurso da modernidade?

Como se sabe, no Discurso filosófico da modernidade, Habermas reconstrói as variantes do discurso pós-moderno, notadamente a ontologia fundamental de Heidegger, a crítica de Bataille, a desconstrução de Derrida e a genealogia e teoria do poder de Foucault. Essas filosofias, nas quais se reconhece a influência de Nietzsche, inspiram ou afirmam uma despedida da modernidade, que é identificada como o terreno histórico-social em que se objetiva a razão dominadora da Aufklärung. A figura de pensamento predominante é aquela de uma crítica radical da razão que intenta desmascarar, no interior do processo de esclarecimento e modernização, os mecanismos de subjugação de que se dota a razão moderna. Os pós-modernos dão adeus à modernidade, pretendendo estar livres dos pressupostos da tradição racionalista e, em última instância, da autocompreensão moderna que surgiu no seio daquela tradição.

Neste contexto, Habermas afirma que foi Hegel quem primeiro forneceu um conceito preciso de modernidade e deu as coordenadas em que se move o discurso moderno, isto é, a dialética da Aufklärung. Seria preciso reconstruir o 
conceito hegeliano de modernidade a fim de avaliar, à maneira de um teste, até que ponto a postura pós-moderna pode realmente dispensar as premissas validadas por Hegel em seu diagnóstico da modernidade.

Duas determinações são essenciais no diagnóstico hegeliano: primeira, o que Habermas denomina consciência histórica da modernidade. Isto significa que os tempos modernos ou novos tempos são expressões que evidenciam a autoconsciência da modernidade de se situar no tempo como uma época histórica, ao mesmo tempo apartada, a cada nova modernidade ${ }^{1}$, do período anterior, e, com isto mesmo, refletindo-se a partir dessa separação. É assim que também os novos tempos se situam em relação ao futuro, como presente carregado de expectativas. À medida que a consciência histórica se localiza no tempo presente, a modernidade passa a exigir para si uma normatividade que não pode ter origem e fundamento em épocas pretéritas, mas deve basear-se em si mesma. Tal exigência se reflete sobretudo no domínio da arte, em que progressivamente o classicismo perde sua hegemonia.

No desenvolvimento do pensamento hegeliano, essa exigência surge quando Hegel percebe que a interação social, compreendida sob o nome de eticidade, não pode ser pensada normativamente com o auxílio dos modelos da pólis grega ou das comunidades do cristianismo primitivo ${ }^{2}$. A época deve ser considerada a partir do desenvolvimento da subjetividade moderna, da sociedade burguesa e do Estado moderno. Hegel analisa então sua época como época de alienação e cisões. O princípio da modernidade é, para ele, o princípio da subjetividade, a qual, desenvolvida sobretudo pela filosofia da reflexão, promove uma série de cisões, em que a razão não pode reconciliar os opostos. É assim que, em uma visão retrospectiva, Hegel pôde eleger a filosofia kantiana como reflexão autodeterminante da modernidade, pois configura cisões entre razão teórica e razão prática, entre razão e sensibilidade, entre finito e infinito, entre sujeito e objeto ${ }^{3}$. Isto se deve à estrutura de auto-referência da consciência que cristaliza o poder de objetivação de uma subjetividade; esta, voltada para si própria, objetiva-se e, em relação às coisas do mundo, toma-as como objeto de conhecimento e manipulação. Por isso, a razão da filosofia da consciência e da Aufklärung é repressora e incapaz de reconciliar. Com a exigência de superar as cisões a partir do seu princípio gerador, a subjetividade, Hegel elabora um conceito de razão como absoluto e espírito. Com isso, ele sai dos limites paradigmáticos da consciência solitária que lida com objetos, mas permanece 
preso aos pólos do paradigma da filosofia do sujeito, ao supor o absoluto como sujeito capaz de pôr e negar o objeto, isto é, um sujeito que tem sua substância no movimento dialético de posição e negação. Com esse conceito de absoluto, Hegel identificou o real e o racional, de tal modo que a razão já se realizou substancialmente na história. Dessa perspectiva, a crítica da modernidade deve se calar. Hegel contraria assim os interesses do espírito moderno pelo presente, já que ele está nivelado em relação ao futuro.

Contudo, Hegel desenrolou a dinâmica que deve assumir o discurso da modernidade: a saber, a dialética da Aufklärung. Esta dialética é compreendida como movimento de emancipação e dominação simultâneas e é desenvolvida de modo imanente a partir do princípio da modernidade. A razão, ao nos esclarecer sobre o mundo e a natureza, acarreta, por meio de seu mecanismo de objetivação, um domínio sobre o sujeito cognoscente e agente, correlato ao domínio sobre a natureza. Ela libera forças emancipatórias ao mesmo tempo que possibilita formas modernas de dominação.

Assim, Hegel pôde fazer um diagnóstico da modernidade, compreendendo suas cisões como a necessidade da filosofia. A filosofia se faz necessária quando o todo da vida se fragmenta em opostos aparentemente irreconciliáveis. Dispondo do conceito de absoluto como totalidade, ele procurou relativizar os opostos absolutizados pela subjetividade e reencontrar, no seio da razão, o poder de unificação que antes estava com a religião. Ele considerou assim o presente como matéria da filosofia, elevando-o ao conceito. Ou seja, Hegel introduziu como matéria da filosofia diagnósticos de época (cf. Habermas 1, p. 66; trad. p. 58).

É certo que para Hegel seu programa não rompia com a tradição, já que toda filosofia é o presente traduzido em pensamentos, e este presente é cada momento da realização da razão na história. Ele pôde assim entender seu pensamento como continuidade. Mas a geração posterior percebeu que o corte com a tradição só à força não seria efetivado. Habermas cita um texto exemplar da nova consciência sobre tal ruptura. O texto é de Arnold Ruge, de 1841: “A filosofia hegeliana mostra já no primeiro estágio de sua evolução histórica um caráter essencialmente diferente do desenvolvimento de todos os Sistemas que existiram até hoje. Esta filosofia, que primeiro declarou que toda filosofia não era outra coisa que o pensamento de seu tempo, foi a primeira também que reconheceu a si própria como este pensamento do tempo. O que as filosofias 
anteriores eram inconsciente e apenas abstratamente, a filosofia hegeliana o é de modo consciente e concreto. Por isso, pôde-se dizer delas que eram e permaneceram somente pensamentos. Porém, aquela de Hegel se apresentou como o pensamento que não pode permanecer enquanto tal, mas que se deve tornar ato. Neste sentido, a filosofia hegeliana é a filosofia da revolução e a última de todas as filosofias em geral.” (Habermas 1, p. 65; trad. p. 57-8).

Derradeiro momento da tradição, a filosofia hegeliana traz em si, segundo os jovens hegelianos, a necessidade de sua transformação em práxis. Ela rompe com a tradição dos grandes sistemas. A partir desse momento, multiplicam-se as manifestações desse fim da filosofia. Mesmo que os sentidos da superação da filosofia, que vão de Marx e os jovens hegelianos até Wittgenstein e Adorno, passando por Nietzsche e Heidegger, sejam bastante diferentes, eles não escondem este corte com a tradição.

Mas este é só um dos traços característicos do discurso da modernidade que se desenvolve até hoje. Os jovens hegelianos fizeram o discurso perdurar também pela sua radical ruptura com o conceito hegeliano de razão. Com este conceito, Hegel acaba voltando-se contra a própria necessidade da filosofia, ao declarar realizada a razão na história, ao identificar o real e o racional, a essência e a existência. A partir daí, o horizonte da história é unidimensionalizado a tal ponto, que o espírito da modernidade não seria outra coisa que um espírito caprichoso incapaz de compreender o sentido da história. Os jovens hegelianos reagiram a essa sobreposição da razão de diferentes formas. Feuerbach opôs o peso da existência ao privilégio idealista do categorial; Kierkegaard insistiu na existência histórica do indivíduo; e Marx, por sua vez, no ser material dos fundamentos econômicos da vida coletiva. Os três procuram, cada um a seu modo, retirar o espírito e a razão da dimensão sublime em que foram conceituados por Hegel, dimensão que resolve as contradições do presente somente em pensamentos. Ao mesmo tempo, eles conservam a idéia de uma razão na história no interior de um pensamento radicalmente histórico: “O pensamento pós-metafísico assumiu no início a forma de uma crítica ao idealismo do tipo hegeliano. A primeira geração dos discípulos de Hegel criticou na obra do mestre a preponderância secreta do geral, do atemporal e do necessário sobre o particular, mutável e casual, portanto, a moldura idealista do conceito de razão (...) Os jovens hegelianos tiveram a capacidade de, em nome da objetividade, da finitude e da faticidade, conferir força de convicção ao desiderato de uma razão produzida 
na história da natureza encarnada corporalmente, situada socialmente e contextuada historicamente” (Habermas 3, p. 48).

A noção de um conceito de razão situada historicamente, herdada em certa medida de Hegel, leva a contradizer o sistema hegeliano. Do mesmo modo, a exigência de realizar a filosofia, assinalada por Ruge, não esconde a crítica da filosofia da reconciliação, pois esta acaba somente reconciliando o presente em pensamentos, deixando o presente enquanto tal em seu estado conflituoso. Isto é notório sobretudo na filosofia política de Hegel. O conceito substancial de Estado, que supera a sociedade civil, permite a Hegel entendê-lo como unidade do universal e do singular, das instituições sociais e políticas com o indivíduo moderno, que então já se compreende segundo estruturas normativas universalistas desenvolvidas na época moderna: autonomia do indivíduo, universalismo moral e legal, etc. No entanto, já o Prefácio da Filosofia do direito, com seu forte ataque àqueles que na época ainda querem fundar o Estado e o direito segundo critérios subjetivistas e utópicos, e as críticas de Hegel dirigidas à reforma eleitoral que tramitava no Parlamento inglês revelam que só com a força do conceito a modernidade pode ser tomada como uma época reconciliada, em que os antagonismos da sociedade civil burguesa seriam harmonizados na esfera política de uma viva eticidade.

A razão é situada historicamente, mas sem que se caia em um relativismo ou em um historicismo. A intenção crítica de buscar na história as resoluções para as crises da modernidade não pode ceder à concepção historicista de que em uma forma objetiva se expressa a particularidade de uma cultura em cada caso única. Para tanto, é preciso atribuir à modernidade uma relação privilegiada com a razão. Por este ângulo, não é paradoxal - como quer Karl Löwith - a orientação pela história na história. A recusa da razão omnisciente de Hegel não tem como contrapartida a ausência de padrões imanentes para uma crítica histórica.

Mas, então, como se dá essa relação entre razão e modernidade, se com a expressão "racionalidade" não se acompanham significados metafísicos, seja da ordem ontológica e teológica, seja da ordem teleológica ou transcendental enquanto faculdade subjetiva? De que modo se dispõe de critérios para uma crítica da modernidade se se situa a razão na história? Segundo Habermas, a esta altura do discurso da modernidade, tornou-se possível registrar padrões estruturais nos desenvolvimentos históricos, padrões que indicam caminhos 
seguidos por processos de formações supra-subjetivas, processos estes que não terminaram, ou foram interrompidos ou mal dirigidos, e que se constituem como processos de aprendizagem e desaprendizagem. A reprodução de formas da vida permite a esta perspectiva moderna detectar tais padrões estruturais e, a partir deles, certificar-se dos rumos históricos. Os limites desses padrões não dizem respeito portanto somente aos limites culturais que lhe são correspondentes em um certo período histórico, como insistiria um historicista.

A nova dialética da Aufklärung, motivada pelos jovens hegelianos, dispensa um conceito metafísico e megalomaníaco de razão em favor de um conceito elaborado de modo histórico e filosófico, dependente da modernização social e cultural. Como seu mestre, os hegelianos estão convencidos de que as insuficiências da modernidade e da Aufklärung só podem ser superadas por um esclarecimento ainda mais radical, mas desta vez centrado nas objetivações de estruturas racionais no mundo moderno burguês. A modernidade cultural e social forma os padrões racionais da crítica aos desenvolvimentos históricos, aos desvios que toma a modernização e aos usos ideológicos das idéias burguesas. A crítica da ideologia é uma figura de pensamento cara a essa tradição que se inicia com os hegelianos de esquerda e se consolida no marxismo ocidental. Ela deixa entrever como o conceito de razão é desenvolvido a partir de processos históricos, pois toma como fundamento normativo da crítica o potencial de racionalidade inscrito nos ideais burgueses e na cultura moderna, que, por seu uso afirmativo como ideais já realizados ou encaminhados para a sua efetivação a fim de legitimar a ordem existente, se tornam ideologia ${ }^{4}$.

Entretanto, talvez a ilustração mais instrutiva dessa posição da crítica da modernidade podemos encontrá-la no próprio Habermas, com sua idéia de incompletude do projeto moderno. A modernidade cultural, como a caracteriza Weber, constitui-se por um progressivo desencantamento do mundo e pela diferenciação de esferas de valor, que, circunscritas a seus âmbitos de legalidade, podem desvincular-se da tradição. Criam-se assim as condições de especialização da cultura e, com isso, o aumento da distância entre o público e a cultura de especialistas, entre setores especializados de trabalho e as tradições que se desenvolvem no mundo da vida. "Aquilo que se acrescenta à cultura, mediante elaboração e reflexão, não chega sem mais ao domínio da prática do dia-a-dia. Ao contrário, com a racionalização cultural, o mundo da vida, desvalorizado em sua substância tradicional, ameaça empobrecer. Ora, o projeto da modernidade, 
formulado no séc. XVIII pelos filósofos do Iluminismo, consiste em desenvolver imperturbavelmente, em suas respectivas especificidades, as ciências objetivantes, os fundamentos universalistas da moral e do direito, e a arte autônoma, mas, ao mesmo tempo, consiste também em liberar os potenciais cognitivos assim acumulados de suas elevadas formas esotéricas, aproveitando-os para a prática, ou seja, para uma configuração racional das relações de vida” (Habermas 2, p. 110). Mas este projeto mostrou-se incompleto, já que a "configuração racional das relações de vida" significa a busca não somente do domínio técnico da natureza, que foi amplamente realizado, mas também da emancipação da sociedade humana e da constituição de formas melhores de vida, o que se tornou duvidoso com o desenvolvimento da modernização capitalista.

Essa concepção da relação entre razão e história marca, a partir dos jovens hegelianos, o discurso filosófico da modernidade por inteiro. Neste discurso, “a razão não é considerada nem como algo pronto e acabado, como uma teleologia objetiva que se manifesta na natureza ou na história, nem como uma mera faculdade subjetiva (...). Deste modo, é precisamente a esfera do não-ente e do mutável que o discurso da modernidade coloca sob a alçada das determinações da compreensão e do erro: o discurso traz a razão a um domínio que tanto a ontologia dos gregos como a filosofia do sujeito dos tempos modernos tinham considerado pura e simplesmente como não tendo sentido e como não sendo suscetível de ser teorizado. Esta arriscada empresa resvalou, primeiramente, ao assumir falsos modelos teóricos, para o dogmatismo da filosofia da história, e provocou, em seguida, a reação de defesa do historicismo. Mas aqueles que fazem o discurso com seriedade sabem que têm de passar por entre Cila e Caríbdis” (idem 1, p. 69; trad. p. 60, nota).

É também a partir dessa concepção de racionalidade e história, centrada na idéia de processos históricos supra-subjetivos de aprendizagem e desaprendizagem, que se torna possível explicar os outros traços característicos do discurso, como a crítica da razão centrada no sujeito, a posição de destaque dos intelectuais e a responsabilidade pela continuidade ou descontinuidades históricas. Não caberia aqui analisar a reconstrução de Habermas dessas características, em seu desenvolvimento nos três partidos que se formam após Hegel, que são os hegelianos de esquerda, os de direita e Nietzsche. Gostaria apenas de acentuar aquilo que estes aspectos guardam com a relação entre modernidade 
e racionalidade. A crítica da razão centrada no sujeito denuncia os mecanismos de controle que se entrevêem já no modo como a autoconsciência manipula objetos da natureza externa e interna, à custa de uma auto-objetivação. Desse modo, o conhecimento que visa a emancipação do homem é transformado em um meio sutil, quase inatacável, de dominação na sociedade. A racionalidade intrumental se verifica assim em processos de socialização modernos. Esses processos de socialização podem ser encarados de diferentes formas. Os hegelianos de esquerda querem com a revolução mobilizar os potenciais racionais emancipadores inscritos naqueles processos supra-subjetivos, para superar o uso racional de dominação no mundo burguês.

Também a razão na história é o objeto dos intelectuais que, atentos a processos de auto-ilusão, apontam para desvios de formações sociais e culturais. É assim que surge a questão da responsabilidade pelas decisões do presente que abrem ou fecham perspectivas futuras, isto é, uma responsabilidade pela continuidade do momento ou pela revolução.

Em resumo, essas características do discurso ${ }^{5}$, à medida que se formaram na crítica da modernidade adiantada pelos jovens hegelianos, e à medida que dão seus sinais ainda no séc. XX, corroboram a tese da contemporaneidade com o séc. XIX, embora o recorrente prefixo “pós” dissimule, com seu jogo de sobreposições, essa contemporaneidade. Desse modo, como os três aspectos mencionados do discurso se interligam sobretudo pela relação entre racionalidade e modernidade, essa relação é essencial na continuação do discurso.

\footnotetext{
Abstract: Our aim is to investigate the meaning of the Habermasian thesis, according to which the philosophical discourse of modernity remains contemporary to the first generation of Hegel's followers, who established a new conception of the historical rationality based on the critique of the Hegelian concept of reason.

Key-words: modernity - reason - history - Hegelianism
} 


\begin{abstract}
Notas
1. O termo "moderno" não teve apenas o emprego de demarcar as fronteiras com o mundo medieval, hoje usual na periodização histórica: "Com conteúdos variáveis, a 'modernidade' sempre volta a expressar a consciência de uma época que se posiciona em relação ao passado da Antiguidade, a fim de compreender a si mesma como resultado de uma transição do antigo para o novo" (Habermas 2, p. 100).

2. O que era o caso ainda para o próprio Hegel em sua juventude. A crítica da positividade ética é marcada em seu fundo pelas sugestões normativas do passado idealizado correspondente à pólis e ao cristianismo primitivo, como contrapartida das cisões e alienações da época moderna (cf. Habermas 1, cap. II).

3. Hegel, e não Kant, foi o primeiro a dar um conceito preciso de modernidade, ao formular como cisão as diferentes esferas de valores da modernidade cultural, para empregar termos weberianos, que se reflete diretamente nas três críticas. Para Hegel, a filosofia crítica exprimia em pensamentos o mundo moderno, a separação e autonomia da ciência, da moral e da arte, mas não refletia suficientemente sobre o caráter histórico da época, de seu afastamento do conteúdo normativo do passado, nem era capaz de dotar a razão do princípio de unificação e da totalidade que se encontrava anteriormente na religião (cf. Habermas 1, cap. II).
\end{abstract}

4. Porém, é preciso observar que a crítica da ideologia sempre esteve ancorada em uma filosofia da história marcada pelo seu caráter teleológico. A teoria crítica, que tornou mais relevante a crítica da ideologia, esperava que o potencial de racionalidade na cultura burguesa fosse efetivado pelo desenvolvimento das forças produtivas, que tornou possível o acúmulo de forças emancipatórias, e conduzisse finalmente à efetivação da razão mediante movimentos sociais. Um dos pontos centrais da crítica de Habermas ao marxismo ocidental e aos primeiros teóricos da Escola de Frankfurt em particular diz respeito justamente a esta concepção de filosofia da história que deveria garantir os fundamentos normativos da teoria crítica da sociedade. A censura é constante na obra de Habermas e tem múltiplas conseqüências para a reconstrução do materialismo histórico (cf. Habermas 4, p. 539-542).

5. Trata-se de características do discurso da modernidade encaradas no núcleo das relações entre racionalidade, consciência de época e modernidade. Elas não esgotam todas as demais características do pensamento "pós-metafísico", no qual se move o discurso, e que dizem respeito aos problemas epistemológicos, 
práticos e estéticos que foram gerados na crítica da metafísica. Igualmente a problemática atual do pensamento pós-metafísico não se diferencia radicalmente da posição dos primeiros discípulos de Hegel (cf. Habermas 3, p.4).

\section{Referências Bibliográficas}

1. HABERMAS, J., Der philosophische Diskurs der Moderne. Frankfurt, Suhrkamp, 1985. Discurso filosófico da modernidade. Trad. A.M. Bernardo e outros. Lisboa, Publicações Dom Quixote, 1990.

2. _ "Modernidade - um projeto inacabado". Trad. M. Suzuki. In: ARANTES, O.B.F. e ARANTES, P.E., Um ponto cego no projeto moderno de Jürgen Habermas. São Paulo, Brasiliense, 1992.

3. Pensamento pós-metafísico. Trad. F.B. Siebeneichler. Rio de Janeiro, Tempo Brasileiro, 1990.

4. Teoría de la acción comunicativa. Trad. M.J. Redondo. Madri, Taurus, 1988, t. II. 